\title{
Obstetric anaesthesia and analgesia for pregnant women with COVID-19: a narrative review with practical considerations
}

\author{
Weijia Du ${ }^{1}$, Lulong $\mathrm{Bo}^{2}$, Zhiqiang Liu ${ }^{1}$, Jinjun Bian ${ }^{2}$, Zhendong $\mathrm{Xu}^{1}$, Fuyi Shen ${ }^{1}$, and
} Xianjin Zhou ${ }^{1}$

${ }^{1}$ Shanghai First Maternity and Infant Hospital

${ }^{2}$ Changhai Hospital

May 18, 2020

\begin{abstract}
During the COVID-19 pandemic, labour and delivery are not going to be put on hold. Managing anaesthesia for patients with COVID-19 will be a challenge, but there is little available data. Having reviewed the literature and the recommendations of experts, and the knowledge gained from the SARS epidemic, this article examines contemporary thinking regarding COVID-19 and pregnancy, the advantages and difficulties of various forms of anaesthesia, and a number of practical considerations related to the management of obstetric analgesia and anaesthesia for pregnant women with the disease.
\end{abstract}

\section{Hosted file}

manuscript.edited(BJOG) ·pdf available at https://authorea.com/users/323112/articles/451983obstetric-anaesthesia-and-analgesia-for-pregnant-women-with-covid-19-a-narrative-reviewwith-practical-considerations 